\title{
Epidemiology of Cataract in the Mexican Population, by 2020
}

\author{
Cruz González R* \\ Epidemiology of Cataract in the Mexican Population, Mexico \\ *Corresponding author: Cruz González R, Epidemiology of Cataract in the Mexican Population, Mexico
}

Submission: 海 July 31, 2017; Published: 笽 December 15, 2017

\begin{abstract}
Summary: The objective of this study is to describe, in a retrospective and prospective manner, statistical data on the revalence and incidence of cataract in the Mexican population from data generated by INEGI (Instituto Nacional de Estadisticas Geografica e Informatica - National Institute of Statistics, Geographical and Informatics) and The CONAPO (Consejo Nacional de Poblacion-National Population Council). The OPS (Organizacion Panamericana de Salud) (PAHO (Pan American Health Organization)) has determined 5 priority eye diseases in Latin America, Cases of which CATARATA causes $50 \%-60 \%$ of reversible blindness. $20 \%$ of the population is above 50 years of age and $65 \%$ have visual disability.
\end{abstract}

Methodology: Statistical analysis with percentage and linear rojection analysis up to the year 2020 in the incidence of cataracts in the Mexican population over 50 age.

Results: Visual Disability data generated by INEGI and OMS from 2010 indicated that 19 million people are 50-80 years of age out of a total of 112.3 million Mexican inhabitants. Of that 19 million, 65\% will have some form of visual impairment., i.e.., 12.3 million people of whom $60 \%$ could have some form of cataracts (7.4 million people). Visual disability data given by INEGI and OMS from 2010, Present the following results based on a total population of 112.3 million of Mexican habitants, we have that 19.0 million people between 50 and 80 years of age. $65 \%$ of the people between 50 and 80 years old will have some form of visual impairment, which is equivalent to 12.3 million habitants; from this number $60 \%$ could had cataracts which is equivalent to 7.4 million people with cataracts in 2010.

Conclusion: The incidence of cataract increases with age, and is more prevalent in, very advanced age. Since women in general tend to outlive men, it is expected that cataracts to be even more prevalent in women. Projections indicate that the world population will increase by a third in the next 15 years, consequently as people are living longer it is expected that people over 65 years old will double in the same period of time [1]. In Mexico projections have shown that by 2020 almost $20 \%$ of the population will be over 50 years old, corresponding to 23 million people, many of whom will have visually significant cataracts in need of surgery.

Keywords: Epidemiology; Prevalence; Incidence; Cataract; Visual acuity; Opacity of the lens

\section{Introduction}

With the increase in the aging population of in the Mexico, chronic diseases such as diabetes mellitus, cardiovascular disease, and hypertension have also become more prevalent. These chronic diseases have consequences on visual health and increase the risk of visually impeding cataracts. Unfortunately current epidemiological studies in Mexico do not provide reliable data about this visual disability. Moreover, this aging of the Mexican population is also an independent risk factor for age-related cataracts [1-3].

According to the World Health Organization (WHO) there are approximately 285 million visually impaired people in the world, of whom 39 million are blind and 246 million have low vision [2]. Approximately $90 \%$ of the global burden of visual impairment is concentrated in developing countries. The main causes of visual impairment are: uncorrected refractive errors: 43\%; Cataracts: $33 \%$; and Glaucoma $2 \%[2,3]$.
Globally, in middle- and low-income countries, cataracts continue to be the leading cause of reversible blindness. Eighty percent of the world's total cases of visual impairment can be avoided or cured [2,3].

About $65 \%$ of the visually impaired are over 50 years old who compromise about $20 \%$, of the world population [2,3]. As the world population ages the number of people at risk for age-related visual impairment will also increase.

Clinically, cataract is defined as, the decrease in visual acuity caused by opacification of the natural lens. It is typically a bilateral disease, $[1,4]$. The only curative treatment, so far, is surgical. This procedure is highly beneficial and cost-effective [1,2]. The surgery, done in a variety of ways, involves surgically removing the opaque natural lens and replacing it with a clear intraocular lens implant. The surgery itself can take as little as 30 minutes or less, 
under sterile conditions but with topical, or local analgesia with minimal anesthesia sedation. developed countries cataract surgery using advanced techniques such as small incisional femto-second assisted laser phacoemulsification has greatly reduced the risk of complications of the surgery and has made visual recovery much faster, many times overnight [1].

I, in spite of the importance of this disease for guiding health policies and services, [5], there are few studies that evaluate the prevalence of this disease in the general population. This is likely, due to the logistical difficulties of carrying out clinical measurements in a large number of people, in addition to the large amount of economic resources and time involved

a. Some governments have initiated programs to prevent, control, and treat visual disabilities. These include.

b. Incorporating ophthalmology services into primary and secondary healthcare systems, with an emphasis on the provision of affordable and high-quality services.

c. The organization of awareness campaigns.

d. The strengthening of partnerships, with the participation of the private sector and civil society.

In countries such as Brazil, ophthalmologic care services have been provided for 10 years through the social security system. China has invested 100 million dollars in cataract surgeries since 2009. India, begining in 1995 has allocated funds for ophthalmology services for the poorest people. [2] In Mexico the Social Protection System in Health has included cataract surgery beginning in 2004 and corneal transplantation beginning in 2011.

The OECD (The Organization for Economic Cooperation and Development) in its "Health at a Glance report of November 2011" [5] uses as an indicator of HEALTH CARE ACTIVITIES, the number of cataract surgery performed at the country level. The Organizacion Panamericana de Salud (The Pan American Health Organization (PAHO)) [3] in several surveys mention that the prevalence of blindness and visual impairment is more than two times higher among rural and poor people. It is estimated that in Latin American countries per million inhabitants: 5,000 are blind and 20,000 are visually impaired. Of these two thirds of the cases are due to diseases that can be treated

It is relevant to establish precisely the proportion of patients suffering from this disease and who are potential candidates for elective and curative cataract surgery.

\section{Objective}

The objective of this study describes presents the prevalence and incidence of cataract in Mexico using data generated from INEGI (Intituto Nacional de EstadisticaGeografica e Informatica) [(National Institute of Statistics, Geography and Informatics)] and CONAPO (Consejo Nacional de Poblacion) [(National Population Council)] [6,7] in the Mexican population.

\section{Materials and Methodology}

The Information and data provided and published by INEGI in Mexico in 2010 [6] were used as the basis of the general population and the distribution by age, the sex of the population and its geographical distribution were not taken into account, covering all the Mexican territory.

Statistical analysis was performed using percentages, averages, ranks and a linear projection analysis up to 2020 in the possible incidence of cataracts in the Mexican population over 50 years of age.

OMS (Organizacion Mundial de la Salud) [3,2] has determined 5 priority eye diseases in Latin America, of which Cataracts accounts for $50 \%-60 \%$ of cases of reversible blindness. It is mentioned that $20 \%$ of the population is above 50 years of age and of this figure $65 \%$ are visually impaired.

\section{Results}

The data and information given by INEGI [6] in Mexico of the year 2010, and data of percentage of visual disability of the OMS [2], we would find the following numbers based on a total population of 112.3 million Mexican habitants, of whom we have 19.0 million people between 50 and 80 years of age. The overall prevalence of cataracts increased with age, reaching $40 \%$ and more than $60 \%$ in population older than 70 an 75 years respectively [1].

Of these 19.0 million people over 50 - 80 years and over, 65\% will have some form of visual impairment, which would amount to 12.3 million habitants; of which $60 \%$ may have a cataract that would represent a prevalence of 7.4 million people with cataracts in 2010 (Table 1).

Table 1:

\begin{tabular}{|c|c|}
\hline Total Population - Year $\mathbf{2 0 1 0}$ & $\mathbf{1 1 2 , 3 3 6 , 5 3 8}$ \\
\hline 50-59 years old & $8,959,656$ \\
\hline 60-69 years old & $5,433,731$ \\
\hline 70-79 years old & $3,119,417$ \\
\hline 80-years old and over & $1,502,231$ \\
\hline Total between 50-80 years old and over & $19,015,035$ \\
\hline 19.0 millions 65\% have visual disability & $12,359,772$ \\
\hline $\begin{array}{c}\text { 12.3 millions of people are visually disabled; 60\% have } \\
\text { cataracts in Mexico en México with a prevalence in } \\
\text { 2010. }\end{array}$ & $7,415,863$ \\
\hline
\end{tabular}

In order to operate $7,415,863$ million cataracts from 2010 to 2020 , it will be necessary to operate 61,798 monthly in 10 years, without there being or increasing the incidence of cataracts in the Mexican population in the next 10 Years, which is impossible to happen.

The Consejo Nacional de Poblacion (CONAPO) [National Population Council (CONAPO)) [7] in Mexico made the following 
population projections for the years 2010-2050, as national demographic indicators, where the following and data were obtained.

A total population average by 2020 of 127 million inhabitants, with an average life expectancy for men of 73.29 years and for women of 78.28 years. In women it is projected that there will be more than 13 million by 2020, aged 50-78, distributed as follows (Table 2).

\section{Table 2:}

\begin{tabular}{|c|c|}
\hline Age & Population \\
\hline $50-59$ & $6,693,332$ \\
\hline $60-69$ & $4,322,670$ \\
\hline $70-78$ & $2,128,000$ \\
\hline Total & $13,144,002$ \\
\hline
\end{tabular}

With a projection of average population by year 2020, in males older than 50 - 73 years old of 10 million people distributed in the following form according to the ages (Table 3).

Table 3:

\begin{tabular}{|c|c|}
\hline Age & Population \\
\hline $50-59$ & $5,930,352$ \\
\hline $60-69$ & $3,778,018$ \\
\hline $70-73$ & 952,405 \\
\hline Total & $10,660,775$ \\
\hline
\end{tabular}

This means that, based on CONAPO data, there will be an average total population projected by 2020 of more than 23 million people over 50 - 78 years of age, men and women in Mexico (Table 4).

\section{Table 4:}

\begin{tabular}{|c|c|}
\hline Men: 50-73 years old & $10,660,405$ \\
\hline Women: 50-78 years old & $13,144,002$ \\
\hline Total & $23,804,777$ \\
\hline
\end{tabular}

The possible impact of Cataract by the year 2020 according to national population projections of CONAPO [7], presented a population between 50 - 78 years of age, of more than 23 million Mexicans, it is presumed that they would present a $65 \%$ disability Visual equivalent to more than 15 million visually impaired people; And of these $60 \%$ could have Cataract which would result in a figure of more than 9 million people with cataracts by 2020 .

\section{Discussion and Conclusion}

So far, there are no studies of cataract prevalence in the Mexican population, however, information and data provided by INEGI and CONAPO, where possible estimates of prevalence and about the incidence of cataracts, it is difficult to calculate, Possibly because the progression of this disease is slow, which requires extensive periods of follow-up, being complex to establish its starting point. Cataract is one of the leading causes of blindness worldwide [4]. Non-existence of a standardized criterion to define the presence of cataracts makes it difficult to obtain a homogeneous diagnosis. Based on visual acuity only, one of the clinical measures used to demonstrate the degree of affectation in the patient's vision and as one of the criteria to evaluate the presence of cataracts and their surgical treatment.

No studies have been found that present estimates of the prevalence of the disease according to the degree of disability that they generate in the individual. This fact is relevant, since in clinical practice one of the predominant criteria to determine the need for surgical treatment is the functional limitation caused by cataracts, often, regardless of the level of visual acuity or blurriness of the lens [1].

For this reason, the prevalence found informs us about the population impact of this disease, but additional studies are required to quantify the need for cataract surgery.

In studies evaluating the prevalence of cataracts according to the morphological definition (lens opacification) the prevalence is between $15 \%$ and $20 \%$; whereas when the visual acuity associated with lens opacification is considered, there is a greater variability attained a prevalence of up to $30 \%$ in the population of 65 or more years of age in the North London study [8].

Despite the differences in the definition of the disease and the populations studied, cross-sectional, Reidey $[8,9]$ in studies in north London on the prevalence of cataracts, I observed an increase in the prevalence of this associated disease at the age of less than $50-55$ years the prevalence are low, ranging from $0.2 \%$ to $7 \%$, in intermediate age groups (approximately 55-65), cataracts affect about one fifth of the population of that age and , From 70/75 years, cataracts affect between $40 \%$ and more than $60 \%$ of the population.

Women have more cataracts than men and these differences tend to increase with age. Some explanations given to this phenomenon are the greater survival of women, their exposure to cataract risk factors linked to reproduction, and differences in access to and use of health services [9].

If we use the percentages Reidey refers to in his study in north London and apply them to INEGI figures and data for the year 2010 and projections made by CONAPO for the year 2020 in Mexico, the results (The highest value in black was taken) of prevalence, as shown in Table 5, of more than 3.5 million cataracts in Mexico.

In conclusion, cataract is a disease especially associated with the aging process, with a growing incidence in very advanced age groups and affecting the female population in a more pronounced way. This profile allows us to foresee an increasing importance of this disease, given the marked process of population aging in many countries. 
Table 5:

\begin{tabular}{|c|c|c|c|}
\hline $\begin{array}{c}\text { Range of Ages Included Both } \\
\text { Sexes }\end{array}$ & INEGI Year 2010 & $\begin{array}{c}\text { Reidey's Studies: \% Of Cataracts } \\
\text { Found According To Age Range }\end{array}$ & Cataracts Prevalences Results \\
\hline $50-59$ years & $8,959,656$ & $0.2-7 \%$ & 627,175 \\
\hline $60-69$ & $5,433,731$ & $20 \%$ & $1,086,746$ \\
\hline $70-79$ & $3,119,417$ & $40-60 \%$ & $1,871,650$ \\
\hline TOTAL & $17,517,804$ & & $3,585,571$ \\
\hline
\end{tabular}

As a result projections indicate that the world population will increase by a third in the next 15 years, while those over 65 will more than double in the same period [10]
Mexico is also part of this phenomenon, projections shown that by 2020 almost $20 \%$ of the population will be over 50 years old, which corresponds to more than 23 million people [7], who would be candidates to suffer senile cataract and limited vision (Table 6).

Table 6:

\begin{tabular}{|c|c|c|c|}
\hline Ages & CONAPO by $\mathbf{2 0 2 0}$ & $\begin{array}{c}\text { Studies of Reidey's results: \% of } \\
\text { cataracts according ages ranges. }\end{array}$ & $\begin{array}{c}\text { Possible result of cataracts } \\
\text { incidency }\end{array}$ \\
\hline $50-59$ years & $12,623,684$ & $0.2-7 \%$ & 883,657 \\
\hline $60-69$ & $8,100,688$ & $20 \%$ & $1,620,137$ \\
\hline $70-79$ & $3,080,405$ & $40-60 \%$ & $1,848,243$ \\
\hline TOTAL & $23,804,777$ & & $4,352,037$ \\
\hline
\end{tabular}

On the other hand, cataract surgery rates have increased drastically in advanced countries, which have helped reduce the impact of cataracts on the number of people with high degrees of visual impairment and blindness. However, this increase in cataract surgeries, given this scenario of population aging and the expansion of surgical indication criteria, has not managed to reduce the gap between the number of people who need this surgical treatment and the access to it $[11,12]$.

The loss of vision causes enormous human suffering for the affected individual and his family. It also represents a public health problem, an economic and social problem, especially in developing countries where nine out of ten people are blind [7].

The OMS (Organización Mundial de la Salud) notes that 80\% of visual disabilities could be prevented or cured. Specialists warn that if additional resources are not allocated and specific programs are not put in place, by 2020 the global incidence of blindness can double and developing countries will bear this brunt. The costs of education, rehabilitation and loss of productivity due to blindness have a significant impact on individuals, families, communities and nations, particularly in the poorest areas of the country [7].

\section{References}

1. Acosta R, Hoffmeister L, Román R, Comas M, Castilla M, et al. (2006) Revisión sistemática de estudios poblacionales de prevalencia de catarata. Arch Soc Esp Oftalmol 81(9): 509-516.

2. Organización Mundial de la Salud. Ceguera y discapacidad visual. Nota descriptiva No. 282.

3. Organización Panamericana de la Salud y Organización Mundial de la
Salud. 144 Sesión del Comité Ejecutivo. 11 Mayo 2009. Plan de Acción para la Prevención de la Ceguera y de las DeficienciasVisuales Evitables 22-26.

4. Hernandez Silva, Juan R (2004) Resultados del Programa Nacional de Prevención de Ceguera por Catarata. Cuba 2000-2003. Rev Cubana Oftalmol 17(2): 1561-3070.

5. Health at a Glance 2017 OECD. Indicators, November 2017.

6. \%20INEGI.\%20www.inegi.org.mx\%202010.

7. Consejo Nacional de Población, Proyección de la Población en México del año 2010 al 2050

8. Reidy A, Minassian DC, Vafidis G, Joseph J, Farrow S, et al. (1998) Prevalence of serious eye disease and visual impairment in a north London population: population based, cross sectional study 316: 16431646.

9. Reidy A, Minassian DC, Desai P, Vafidis G, Joseph J, et al. (2002) Increased mortality in women with cataract: a population based follow up of the North London Eye Study. Br J Ophthalmol 86(4): 424-428.

10. Resnikoff S, Pascolini D, Etya'ale D, Kocur I, Pararajasegaram R, et al. (2004) Global data on visual impairment in the year 2002. Bull World Health Organ 82(11): 844-851.

11. Minassian DC, Reidy A, Desai P, Farrow S, Vafidis G, et al. (2000) The deficit in cataract surgery in England and Wales and the escalating problem of visual impairment: epidemiological modelling of the population dynamics of cataract. Br J Ophthalmol 84(1): 4-8.

12. Lundstrom M, Stenevi U, Thorburn W (2001) Age-related utilisation of cataract surgery in Sweden during 1992-1999. A retrospective study of cataract surgery rate in one-year age groups based on the Swedish National Cataract Register. Acta OphthalmolScand 79(4): 342-349.

13. Landin SM, Romero Sanchez RE (2006) La ceguera y bajavisiónen el mundo:: ¿un problemamédico o social?. Rev Hum Med 6(2): 1727-8120. 